\title{
Silylium-Catalyzed Carbon-Carbon Coupling of Alkynylsilanes with (2-Bromo-1-methoxyethyl)arenes: Alternative Approaches
}

\author{
Belén Rubial, Alfredo Ballesteros, ${ }^{\star}$ and José M. González* \\ Dedication ((optional))
}

\begin{abstract}
The catalytic activation of alkynylsilanes towards 2-halo-1alkoxyalkyl arenes gives $\beta$-halo-substituted alkynes. It involves the chemoselective substitution of an alkoxyde by an alkyne in the presence of a neighbour $\mathrm{C}\left(\mathrm{sp}^{3}\right)-\mathrm{Br}$ bond in a cationic $\mathrm{C}-\mathrm{C}$ bondforming event. Two complementary protocols to accomplish this new transformation are reported. The outcome of a direct approach based on mixing the precursors with a freshly prepared solution of the active catalytic species ( $\left.\mathrm{TMSNTf}_{2}\right)$ is compared with an alternative based on smooth releasing the required silyliun ions upon selective activation of the alkyne by gold(I) (JohnPhosAuNTf $f_{2}$ ). The two approaches gave satisfactory results to access this otherwise elusive alkynylation process, which furnishes 4-bromo-substituted alkynes and tolerates various functional groups.
\end{abstract}

\section{Introduction}

The discovery of catalytic carbon-carbon bond-forming reactions from readily accessible precursors is of ongoing interest. Moreover, halogen-containing molecules are versatile synthetic intermediates, so contemporary advances in methodology for their synthesis is subject of much attention. ${ }^{[1]}$ Cohalogenation reactions of alkenes provide a flexible entry to $\beta$-heteroatomsubstituted organic halides. ${ }^{[2]}$ Due to the electrophilic nature of these reactions vinyl-substituted arenes are among the most useful substrates for an efficient regioselective preparation of a representative array of $\beta$-halo-derivatives.

The development of new catalytic processes of $\beta$-halo benzyl ethers is desirable to strength their merit as synthetic building-blocks, since they are available in just one-step from simple reagents (alcohols, styrenes and a bromonium donor). Stoichiometric reactions of the carbon-halogen bond were early documented. ${ }^{[3]}$ Later, catalytic transformations were developed and the known processes are now collected in Scheme 1. Thus, the cyclization of $O$-propargylated substrates in the presence of LDA gives hetero- or carbocyclic products featuring a halogenshift (eq 1). ${ }^{[4]}$ Furthermore, the formation of (1-methoxyoctane1,3-diyl)dibenzene (eq 2) was noticed in the alkylation of 2bromo-1-methoxyethyl)benzene with alkyl halides catalyzed by $\mathrm{Cp}_{2} \mathrm{TiCl}_{2},{ }^{[5]}$ suggesting that styrene is released and incorporated into the catalytic cycle. ${ }^{[5 b]}$ Photocatalytic radical cyclizations (eq 4) giving Heck-like products, ${ }^{[6]}$ and nickel-catalyzed Suzuki cross-coupling with boronic acids (eq 5). ${ }^{[7]}$ have been disclosed.

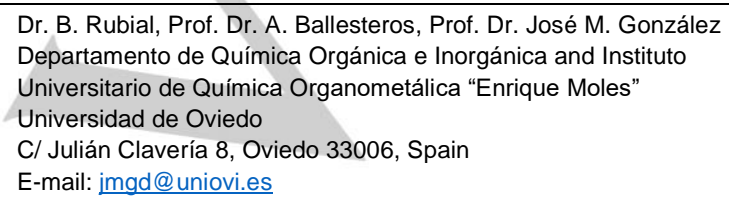

Supporting information for this article is given via a link at the end of the document.((Please delete this text if not appropriate))

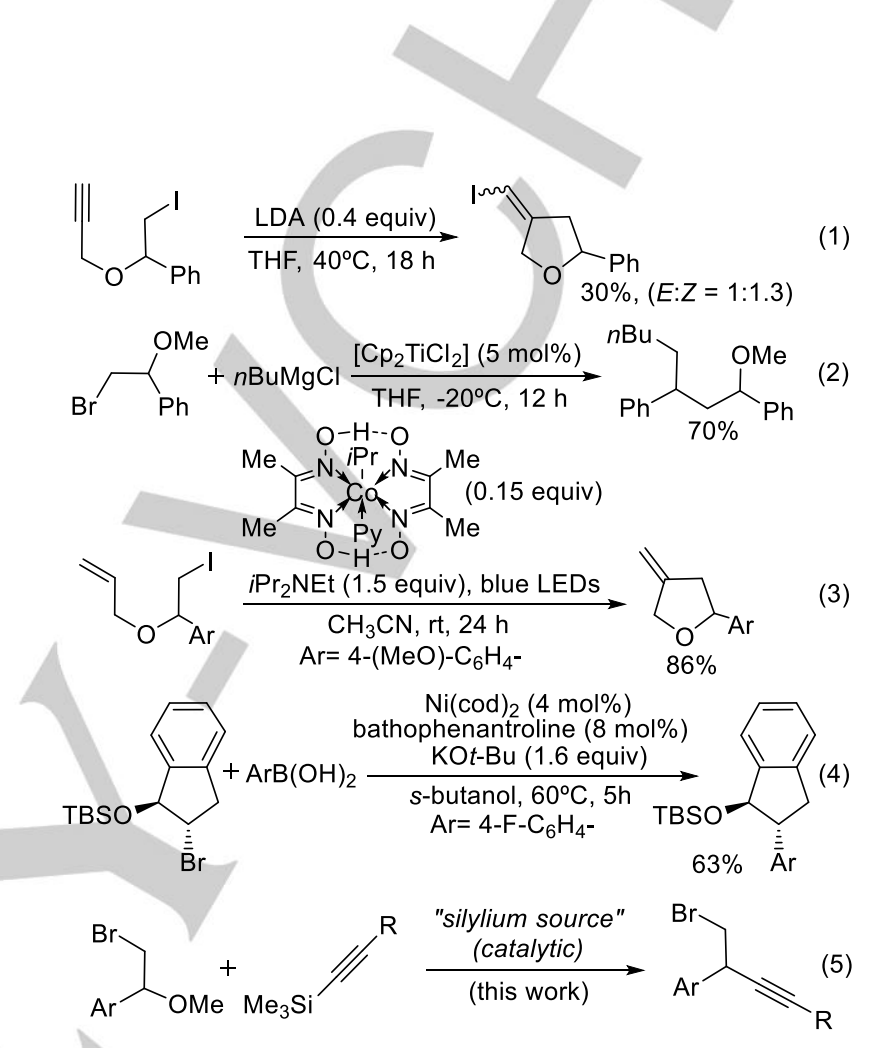

Scheme 1. Catalytic reactions from $\beta$-halo-substituted benzyl ethers.

Herein, a silylium-based catalytic approach to accomplish cross-coupling reactions of trialkylsilyl acetylene derivatives with (2-bromo-1-methoxyalkyl)arenes is presented (eq 5, Scheme 1).

\section{Results and Discussion}

Metal-catalyzed carbon(sp)-carbon( $\left.\mathrm{sp}^{3}\right)$ cross-coupling reactions are relevant to elaborate alkynes. ${ }^{[8]}$ The transition metal-catalyzed $\mathrm{C}(\mathrm{sp})-\mathrm{C}\left(\mathrm{sp}^{3}\right)$ cross-coupling turns elusive for electrophiles containing a vicinal halogen-carbon $\left(\mathrm{sp}^{3}\right)$ bond. ${ }^{[9]}$ In this context, cationic chemistry ${ }^{[10,11]}$ could be helpul to access complementary products. Thus, a catalytic $\mathrm{C}-\mathrm{C}$ bond-forming process from vic-halohydrines preserving unaltered the $\mathrm{C}\left(\mathrm{sp}^{3}\right)$-halogen bond would be a timely advance in the field.

We decided to use (2-bromo-1-alkoxyalkyl)arenes 1 to broach the viability of such a challenging process following the strategy outlined in Scheme 2, which relies on the ability of a silicon-based Lewis acid ${ }^{[12]}$ to activate the sacrificial alkoxy group in the parent substrate 1. Its chemoselective activation would lead to $I$. Next, the benzylic nature of the leaving group would favor the formation of the reactive carbocation II. ${ }^{[13]}$ 


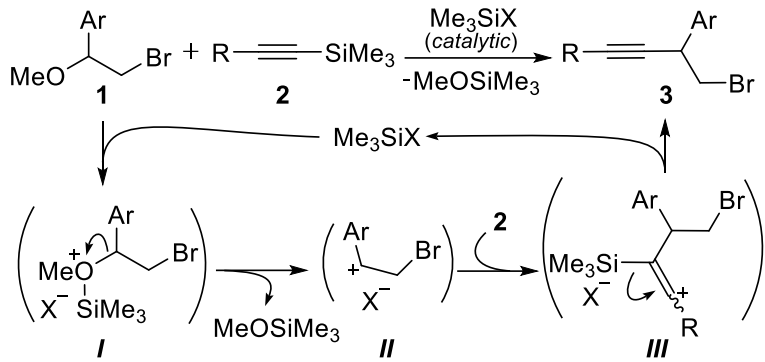

Scheme 2. Hypothesis behind the proposed alkynylation without bromine lost.
Table 1. Evaluation and identification of suitable reaction conditions.

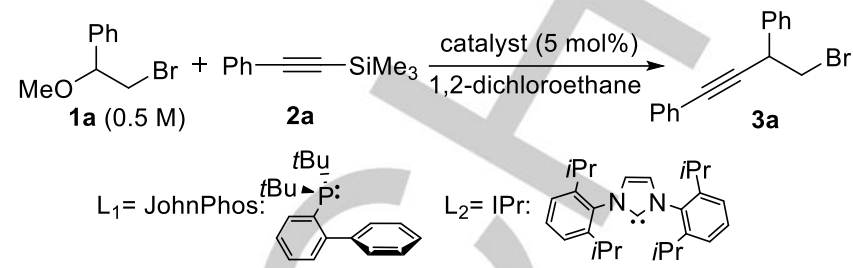

A subsequent nucleophilic attack of the alkynylsilane 2 would afford a $\beta$-silyl stabilized vinyl cation intermediate III, which would be the responsible for the formation of the coupling product $\mathbf{3}$, at the time of regenerating catalytically competent species. At the onset of this approach is the potential of silylium ions to catalyze selective organic reactions. ${ }^{[14-18]}$ Worth noting, there is a scant number of alkynylations based on the use of alkynylsilanes and electrophiles featuring oxygen as a leaving group, mostly limited to sole examples within a context of allylation reactions of cyclic ethers or diaryl methanol derivatives. ${ }^{[19]}$

Results from an initial exploratory study are collected in Table 1 . The activity of commercial trimethylsilyl triflate was first investigated. However, 3a was not formed under the conditions defined in entry 1 . Conversely, the reaction took place using freshly prepared $N$-(trimethylsilyl) bis(trifluoromethanesulfonyl)imide $\left(\mathrm{TMSNTf}_{2}\right)$ as the catalyst ${ }^{[20]}$ (entry 2). Simultaneously, different options for in situ generation of the silylium catalyst were evaluated. Bis(trifluoromethanesulfonyl)imide (triflimide, entries 3-6) was assayed. ${ }^{[15]} \mathrm{A}$ fast reaction giving $3 \mathbf{a}$ was noticed, but it failed to give full conversion of $\mathbf{1 a}$, even over extended reaction times. In terms of alternative precursors, the related reaction of $\mathbf{1 a}$ with phenylacetylene $\mathbf{4 a}$ gave no evidence for coupling leading to $\mathbf{3 a}$. Also, the reaction of phenylacetylene with 2-bromo-1-phenylethanol 5a failed to give the desired product.

Attention was focused on in situ release of the required silylium catalyst by activation of the parent silyl-substituted alkyne with a Lewis acid. ${ }^{[16-17]}$ In this regard, $\mathrm{ZnBr}_{2}, \mathrm{PtCl}_{4}$ and $\mathrm{Cu}(\mathrm{MeCN})_{4} \mathrm{PF}_{6}$ failed to convert 1a, irrespectively of the assayed reaction temperature $\left(20,80\right.$ or $\left.120^{\circ} \mathrm{C}\right) . \mathrm{InCl}_{3}$ activates 1a but it gives only modest yield for $\mathbf{3 a}$ (near 20\%). ${ }^{[21]} \mathrm{AgNTf}_{2}$ and JohnPhosAuNTf ${ }^{[22]}$ [JohnPhos: (2biphenyl)di-tert-butylphosphine] were active precatalyst for a successful initiation step (entries 7-11), with gold(I) giving better yield by increasing the reaction temperature up to $80^{\circ} \mathrm{C}$. Attempts to improve the yield further modifying the temperature were made. Using $\mathrm{TMSNTf}_{2}$ at $80^{\circ} \mathrm{C}$ (entry 12 ) the reaction worked nicely but the isolated yield did not significantly improve that at room temperature (entry 2). The activity of $\mathrm{HNTf}_{2}$ at this temperature was also tested (entry 13), 1a was consumed but the yield for $\mathbf{3 a}$ was slightly lower than for gold, even though for the latter full conversion was not accomplished (entry 10).

\begin{tabular}{|c|c|c|c|c|}
\hline Entry & Catalyst & $\mathrm{T}\left({ }^{\circ} \mathrm{C}\right) / \mathrm{t}(\mathrm{h})$ & Conv. ${ }^{[a]}$ & Yield $^{[b]}$ \\
\hline 1 & TMSOTf & $20 / 12$ & -- & -- \\
\hline 2 & $\mathrm{TMSNTf}_{2}{ }^{[\mathrm{c}]}$ & $20 / 1$ & 100 & 55 \\
\hline 3 & $\mathrm{HNTf}_{2}$ & $20 / 1.5$ & 77 & 63 \\
\hline 4 & $\mathrm{HNTf}_{2}$ & $20 / 4$ & 92 & 53 \\
\hline $5^{[d]}$ & $\mathrm{HNTf}_{2}$ & $20 / 0.7$ & -- & -- \\
\hline $6^{[\mathrm{d}, \mathrm{e}]}$ & $\mathrm{HNTf}_{2}$ & $20 / 1.5$ & -- & -- \\
\hline 7 & $\mathrm{~L}_{1} \mathrm{AuNTf}_{2}$ & $20 / 1.5$ & 51 & 36 \\
\hline 8 & $L_{1} A_{u N T f}{ }_{2}^{[f]}$ & $20 / 4$ & 64 & 30 \\
\hline 9 & $\mathrm{AgNTf}_{2}$ & $20 / 3$ & 60 & 51 \\
\hline 10 & $\mathrm{~L}_{1} \mathrm{AuNTf}_{2}$ & $80 / 1.5$ & 91 & 62 \\
\hline 11 & $\mathrm{AgNTf}_{2}$ & $80 / 0.5$ & 100 & 50 \\
\hline 12 & $\mathrm{TMSNTf}_{2}{ }^{[\mathrm{c}]}$ & $80 / 0.05$ & 100 & 57 \\
\hline 13 & $\mathrm{HNTf}_{2}$ & $80 / 1$ & 100 & 58 \\
\hline 14 & $\mathrm{~L}_{1} \mathrm{AuNTf}_{2}$ & $100^{[\mathrm{g}]} / 0.75$ & 100 & 71 \\
\hline 15 & $\mathrm{~L}_{1} \mathrm{AuNTf}_{2}$ & $120^{[\mathrm{g}]} / 0.25$ & 100 & 73 \\
\hline 16 & $\mathrm{~L}_{2} \mathrm{AuNTf}_{2}{ }^{[\mathrm{h}]}$ & $120^{[\mathrm{g}]} / 0.25$ & 100 & 68 \\
\hline 17 & $\mathrm{~L}_{1} \mathrm{AuNTf}_{2}{ }^{[i]}$ & $120^{[\mathrm{g}]} / 0.65$ & 100 & 30 \\
\hline 18 & $\mathrm{~L}_{1} \mathrm{AuNTf}_{2}{ }^{[g]}$ & $120^{[i] / 0.25}$ & 79 & 20 \\
\hline
\end{tabular}

[a] Conversion calculated by ${ }^{1} \mathrm{H}$ NMR analysis of the crude reaction using 1,3,5-trimethoxybenzene as internal standard. [b] Isolated Yield. [c] Freshly prepared, for experimental details see ESI. [d] Using phenylacetylene 4a as nucleophile. [e] For 2-bromo-1-phenylethanol 5a as electrophile. [f] Using 2a 1M. [g] Heating in a microwave oven. [h] Using toluene as solvent. [i] In 1,4dioxane as solvent.

At $100^{\circ} \mathrm{C}$, the gold-catalyzed process brought about full conversion and higher yield for $\mathbf{3 a}$ (entry 14). Furthermore, considering the nice functional group tolerance typically exhibited by gold catalysis and the exquisite level of chemoselectivity associated with the interaction of alkynes with gold(I) complexes, it was decided to further optimize the reaction time for this approach. Additional improvement was achieved heating at $120^{\circ} \mathrm{C}$ in a microwave oven (entries 15-18). Gratifyingly, only 15 minutes were required for the reaction to afford the coupling product $\mathbf{3 a}$, in $73 \%$ 
isolated yield (entry 15). The fact that $\sigma, \pi$-(alkyne) digold(I) complexes can be formed and their limited activity ${ }^{[23]}$ might account for the beneficial effect of heating over the goldcatalyzed transformations. In fact, ${ }^{31} \mathrm{P}-\mathrm{NMR}$ inspection of the crude reaction mixture corroborated its formation. ${ }^{[21]}$ Likely, heating might allow to dissociate active mononuclear species, ensuring the required concentration of the silicon Lewis acid for a successful coupling. Robust [1,3-bis(2,6diisopropylphenyl)imidazolylidene][bis(trifluoromethanesulfo nyl)imide]gold(I) (IPrAuNTf ${ }_{2}$ ) was tested as precatalyst, but slightly lower yield was recorded. The role of the solvent was evaluated (entries 15, 17 and 18). The reaction in toluene required longer reaction time to consume $\mathbf{1 a}$ and gave lower yield for $\mathbf{3 a}$. The performance of the reaction conducted in 1,4-dioxane was also inferior.

The conditions outlined in entries 2 and 15, in Table 1, were selected as the alternatives for studying the scope of this new catalytic C-C bond-forming event (Scheme 3 ), and are termed as method $A$ (entry 2 ) and method $B$ (entry 15 ).

The compatibility of different halogens with this process was proved (3a-c, Scheme 3). Even iodine atoms are tolerated, but the yield was higher for the case of the bromohydrin. The influence of the substituents located para to the reactive benzylic position was analyzed (3d-h). ${ }^{[24]}$ Electron-donating groups result in short reaction times and good isolated yields. The strong electron-withdrawing carboxylic ester failed to provide full conversion and the yield was only modest. Less electron-withdrawing halide substituents still furnish nice synthetic numbers. Usually, in terms of the yield of products 3 , method $B$ outperforms the results obtained using the preformed silylium catalyst For 3f, the conversion using $\mathrm{TMSNTf}_{2}$ was incomplete. Even after extended reaction time (overnight) it was in the range of the $50 \%$. Anyway, it was a clean reaction out of which the desired product was isolated in $48 \%$ yield.
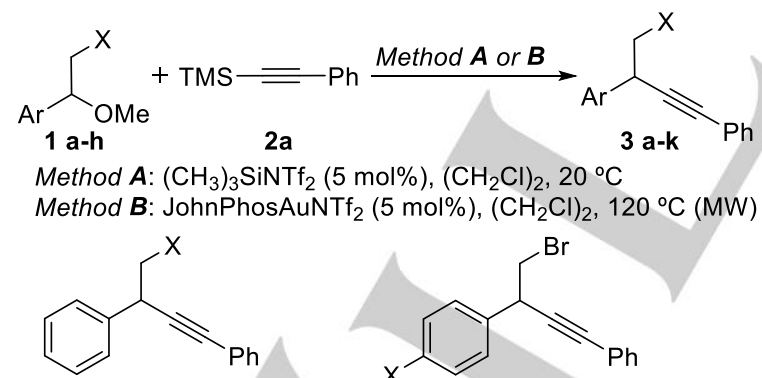

3a: $\mathrm{X}=\mathrm{Br}, 1 \mathrm{~h}, 55 \%(\boldsymbol{A})$, $15 \mathrm{~min}, 73 \%(B)$ 3b: $X=\mathrm{Cl}, 30 \mathrm{~min}, 40 \%(B)$ $3 c: X=1,15 \mathrm{~min}, 52 \%(B)$

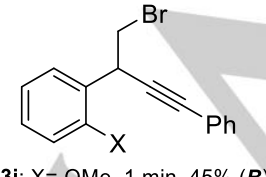

$\min , 45 \%(B)$ 3j: $X=M e, 30 \mathrm{~min}, 77 \%(\boldsymbol{A})$ $10 \mathrm{~min}, 85 \%(B)$

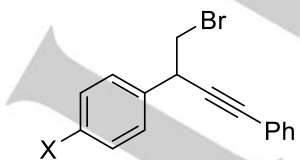

d: $X=O M e, 1 \mathrm{~min}, 73 \%(B)$

3e: $X=M e, 5 \mathrm{~min}, 76 \%(B)$

3e: $X=M e, 5 \min , 76 \%$
3f: $X=B r, 12 h, 48 \%(A)$ $3 \mathrm{~h}, 74 \%(B)$

3g: $\mathrm{X}=\mathrm{CO}_{2} \mathrm{Me}, 6 \mathrm{~h}, 24 \%$ (48\% conv) (B)

3h: $X=F, 30 \mathrm{~min}, 69 \%(\boldsymbol{A})$

$$
1 \mathrm{~h}, 81 \%(B), \mathrm{Br}
$$

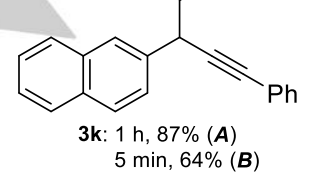

Alternatively, using the gold precatalyst, $74 \%$ yield of $\mathbf{3 f}$ was isolated. Both methods were convenient to prepare fluorinated $\mathbf{3 h}$, offering fast and efficient coupling choices; ortho-substituted precursors are active in this reaction (3i and $3 \mathbf{j}$ ). Remarkably, method $A$ was more efficient to access a 2-naphthyl scaffold present in derivative $\mathbf{3 k}$.

The alkyne scope is shown in Scheme 4. A silyl-masked conjugate enyne gave productive formations of $\mathbf{3}$ I for both $\mathrm{TMSNTf}_{2}$ (Method $A$ ) and gold(I) (Method $B$ ). Both aryl- and alkyl alkynes enter this $\mathrm{C}-\mathrm{C}$ bond-forming process, giving rise to fast reactions ( $3 m$ to $\mathbf{3 p}$ ). Interestingly, remote ester functionality is compatible with this coupling approach, though the product was isolated in moderate yield (see 30).

The reaction was applied to the synthesis of a collection of small molecules showing moderate functional group density within interesting topologies. Attention was focused on a selective and straight synthesis of esters 3q-3t. Only two electrophilic reactions were required, namely, styrene bromoalkoxylation and subsequent catalytic coupling of the assembled $\mathbf{1}$ with alkynylsilane $\mathbf{2}$. These examples validate the merit of this new protocol by selectively preparing an array of simple functionalities, for which other direct conceivable disconnections are not of immediate execution. Besides, allylsilane 6a was a suitable nucleophile for this reaction and nicely furnished $\mathbf{7 a}$.

Regarding the mechanistic hypothesis in Scheme 2, additional experimental work was performed to validate some of the proposed features.

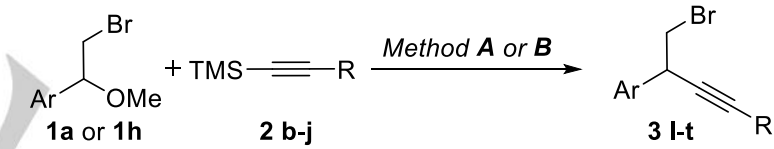

Method A: $\left(\mathrm{CH}_{3}\right)_{3} \mathrm{SiNTf}_{2}(5 \mathrm{~mol} \%),\left(\mathrm{CH}_{2} \mathrm{Cl}\right)_{2}, 20^{\circ} \mathrm{C}$ Method B: JohnPhosAuNTf 2 (5 mol\%), $\left(\mathrm{CH}_{2} \mathrm{Cl}\right)_{2}, 120^{\circ} \mathrm{C}(\mathrm{MW})$

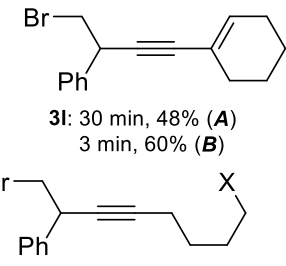

3o: $X=O A c, 5 \mathrm{~min}, 46 \%(B)$ $3 p: X=B u, 55 \mathrm{~min}, 50 \%(A)$ $5 \mathrm{~min}, 51 \%(B)$
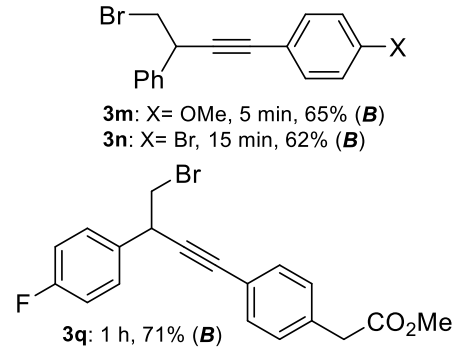<smiles>NC(=O)Cc1cccc(C#CC(CBr)c2ccc(F)cc2)c1</smiles><smiles>COC(=O)[181I-]</smiles><smiles>CCOC(=O)C(CC#CC(CBr)c1ccc(F)cc1)C(=O)OCC</smiles>

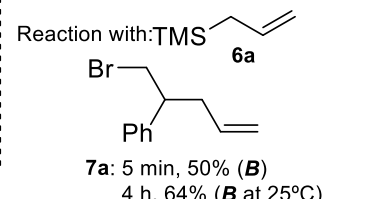

Scheme 4 . Coupling products of $\mathbf{1 a} / \mathbf{1 h}$ with alkynylsilanes $\mathbf{2}$ or allyl silane $\mathbf{6 a}$. 


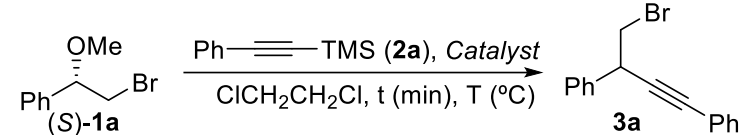

$$
\begin{aligned}
& \text { ee: }>99 \% \\
& \text { Catalyst } \\
& \begin{array}{lrll}
\mathrm{TMSNTf}_{2}(5 \mathrm{~mol} \%) & 15 & 20 & 58 \% \\
\end{array} \\
& \text { JohnPhosAuNTf } 2 \text { (5 mol\%) } 240 \quad 20 \quad 45 \% \text { (conversion: } 64 \% \text { ) }
\end{aligned}
$$

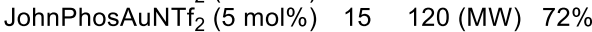

Scheme 5. Stereochemical outcome of the catalytic C-C bond forming event

The involvement of a cationic intermediate as the ultimate responsible for the $\mathrm{C}$-C bond-forming step is supported by the racemization noticed for the coupling reactions of (S)-2-bromo-1-methoxyethyl)benzene (S)-1a with $\mathbf{2 a}$ under the conditions outlined in Scheme 5. ${ }^{[21]}$

A mechanistic rationale is proposed in Scheme 6. For the approach following method $\boldsymbol{B}$, it is proposed that gold species trigger the release of the silylium catalyst, although other role in the coupling could not be firmly ruled out. The invoked reaction of alkynylsilane with $\mathrm{gold}(\mathrm{I})$ is supported by its carbophilic nature ${ }^{[26]}$ and by precedents for the regioselective alkynylsilane activation, which operates under the control of the $\beta$ - silicon effect. $\left.\left.{ }^{[26} \mathrm{b}\right)\right]$ This accounts for the formation of a gold acetylide and the release of the silylium catalyst, which would eventually launch the coupling. The possibility of a neighbouring assisted ether ionization by bromine participation was analysed testing the reaction of a 1:1:1 molar ratio of (1-methoxyethyl)benzene $\mathbf{8 a}, \mathbf{1 a}$ and trimethyl(phenylethynyl)silane $\mathbf{2 a}$ catalyzed by $\mathrm{TMSNTf}_{2}\left(5 \mathrm{~mol} \%\right.$ ). ${ }^{[27]} \mathrm{A}$ qualitative estimation of the relative reactivity's of $\mathbf{1 a}$ and $\mathbf{8 a}$ based on the conversions revealed the former being less reactive, which does not accommodate neighbour assistance. Then, the alkyne would trap the carbocation, and the coupling product will derive from an addition-elimination sequence at the time of regenerating the catalyst.

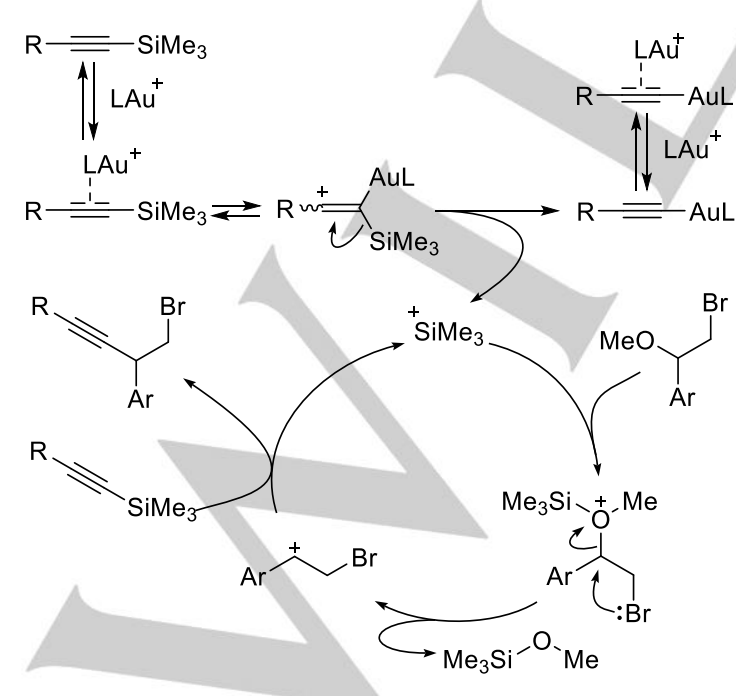

Scheme 6. Proposed mechanistic rational for the coupling process.

\section{Conclusions}

In summary, a catalytic $\mathrm{C}(\mathrm{sp})-\mathrm{C}\left(\mathrm{sp}^{3}\right)$ coupling reaction involving a trimethylsilyl-modified derivative of a terminal alkyne and a benzyl ether having a halogen atom at the $\beta$ alkyl position has been settled. Trimethylsilyl bistriflimidate is an efficient catalyst for this new reaction. Alternatively, rather than starting from the preformed silylium donor, the transformation can be executed by carbophilic activation of silyl-substituted alkynes using a gold precatalyst, which provides a synthetic toggle to get into Lewis acid catalysis. It offers a robust entry into a new C-C bond-forming process that tolerates additional functional groups. Although the accomplished synthetic efficiency is typically higher using the latter approach, the former reveals that silylium ions must be conceptually considered as catalyst to device new coupling process. The reported transformation is well suited to afford products with complementary chemoselectivity to those arising from metal catalysed crosscoupling reactions of halohydrins. Work to expand this chemistry by catalyst improvement and to unveil new aspects of the scope of the reaction for both, the electrophile and the nucleophile, are in progress.

\section{Acknowledgements}

B. R. would like to acknowledge the Spanish Ministerio de Educación, Cultura y Deporte for a FPU predoctoral fellowship. Agencia Estatal de Investigación (AEI), Fondo Europeo de Desarrollo Regional (FEDER) and Consejería de Economía y Empleo, Principality of Asturias are acknowledged for financial aid [Grants CTQ2016-76840-R (AEI/FEDER, UE) and FC-15GRUPIN14-013, repectively].

Keywords: alkyne $\bullet$ cationic $\cdot$ silicon $\bullet$ cross-coupling $\bullet$ catalysis

[1] D. A. Petrone, J. Ye and M. Lautens, Chem. Rev. 2016, 116, 8003 8104

[2] a) J. Rodriguez and J. P. Dulcère, Synthesis 1993, 1177-1205; b) I. Saikia, A. J. Borah and P. Phukan, Chem. Rev. 2016, 116, 6837-7042.

[3] a) T. Sugita, K. Nishimoto, K. Ichikawa, Chem. Lett. 1973, 607-609; b) M. Mikolajezyk, W. Perlikowska, J. Omelanezuk, Synthesis 1987, 10091012; c) T. Fukuyama, X. Chen, J. Am. Chem. Soc. 1994, 116, 3125 3126; d) J. M. Concellón, P. L. Bernad, J. A. Pérez-Andrés, Angew. Chem. 1999, 111, 2528-2530; Angew. Chem. Int. Ed. 1999, 38, 2384 2386; e) Cossy, V. Bellosta, J.-L. Ranaivosata, B. Gille, Tetrahedron 2001, 57, 5173-5182; f) L. Zhou, T. Hirao, J. Org. Chem. 2003, 68 1633-1635; g) F. J. Fañanás, M. Álvarez-Pérez, F. Rodríguez, Chem. Eur. J. 2005, 11, 5938-5944. h) S. E. Denmark, M. T. Burk, A. J. Hoover, J. Am. Chem. Soc. 2010, 132, 1232-1233; i) D. C. Braddock, J. S. Marklew, A. J. F. Thomas, Chem. Commun. 2011, 47, 9051-9053.

[4] a) T. Harada, K. Muramatsu, K. Mizunashi, C. Kitano, D. Imaoka, T. Fujiwara, H. Kataoka, J. Org. Chem. 2008, 73, 249-258. Formally related indium-mediated ATR radical cyclization: b) R. Yanada, Y. Koh, N. Nishimori, A. Matsumura, S. Obika, H. Mitsuya, N. Fujii, Y. Takemoto, J. Org. Chem. 2004, 69, 2417-2422.

[5] a) J. Terao, K. Saito, S. Nii, N. Kambe, N. Sonoda, J. Am. Chem. Soc. 1998, 120, 11822-11823; b) J. Terao, Y. Kato, N. Kambe, Chem. Asian J. 2008, 3, 1472-1478. 
[6] M. E. Weiss, L. M. Kreis, A. Lauber, E. M. Carreira, Angew. Chem. 2011, 123, 11321-11324; Angew. Chem. Int. Ed. 2011, 50, 11125 11128.

[7] a) J. Zhou, G. Fu, J. Am. Chem. Soc. 2004, 126, 1340-1341; see also: b) F. González-Bobes, G. Fu, J. Am. Chem. Soc. 2006, 128, 5360-5361.

[8] a) E. Negishi, L. Anastasia, Chem. Rev. 2003, 103, 1979-2018; selected advances: b) M. Eckhardt, G. C. Fu, J. Am. Chem. Soc. 2003 125, 13642-13643; c) G. Altenhoff, S. Würtz, F. Glorius, Tetrahedron Lett. 2006, 47, 2925-2928; d) J. Caeiro. J. Pérez Sestelo, L. A. Sarandeses, Chem. Eur. J. 2008, 14, 741-746; e) S. W. Smith, G. C. Fu, J. Am. Chem. Soc. 2008, 130, 12645-12647; f) C. A. Correia, C.-J. Li, Adv. Synth. Catal. 2010, 352, 1446-1450; g) L. Zhou, F. Ye, Y. Zhang J. Wang, J. Am. Chem. Soc. 2010, 132, 13590-13591; h) Vechorkin, A Godinat, R. Scopelliti, X. Hu, Angew. Chem. 2011, 123, 11981-11985 Angew. Chem. Int. Ed. 2011, 50, 11777-11781; i) T. Thaler, L.-N. Guo, P. Mayer, P. Knochel, Angew. Chem. 2011, 123, 2222-2225; Angew. Chem. Int. Ed. 2011, 50, 2174-2177; j) J. Y. Hamilton, D. Sarlah, E. M. Carreira, Angew. Chem. 2013, 125, 7680-7683; Angew. Chem. Int. Ed. 2013, 52, 7532-7535; k) Q.-Q. Zhou, W. Guo, W. Ding, X. Wu, X. Chen, L.-Q., Lu, W.-J. Xiao, Angew. Chem. 2015, 127, 11348-11351; Angew. Chem. Int. Ed. 2015, 54, 11196-11199.

[9] a) Metal-Catalyzed Cross-Coupling Reactions and More; (Eds.: A. de Meijere, S. Bräse, M. Oestreich), Wiley- $\mathrm{VCH}, 2014$; b) C. C. C Johansson Seechurn, M. O. Kitching, T. J. Colacot, V. Snieckus, Angew, Chem. 2012, 124, 5150-5174; Angew, Chem. Int. Ed. 2012, 51 5062-5085; c) Z. Qureshi, C. Toker, M. Lautens, Synthesis, 2017, 49 1-6.

[10] Selected reviews: a) R. Naredla, D. A. Klumpp, Chem. Rev. 2013, 113, 6905-6948; b) E. Emer, R. Sinisi, M. Guiteras Capdevila, D. Petruzziello, F. De Vicentiis, P. G. Cozzi, Eur. J. Org. Chem. 2011, 647666.

[11] Selected work: a) P. Rubenbauer, E. Herdtweck, T. Strassner, T. Bach, Angew. Chem. 2008, 120, 10260-10263; Angew. Chem. Int. Ed. 2008 47, 10106-10109; b) S.-K. Xiang, L.-H. Zhang, N. Jiao, Chem. Commun. 2009, 6487-6489; c) M. Niggemann, M. J. Meel, Angew. Chem. 2010 122, 3767-3771; Angew. Chem. Int. Ed. 2010, 49, 3684-3687; d) P. Maity, H. D. Srinivas, M. P. Watson, J. Am. Chem. Soc. 2011, 133 , 17142-17145; e) J. M. Gil-Negrete, J. Pérez Sestelo, L. A. Sarandeses, Org. Lett. 2016, 18, 4316-4319; f) J. A. Fernández-Salas, A. J. Eberhart, S. J. Procter, J. Am. Chem. Soc. 2016, 138, 790-793.

[12] A. D. Dilman, S. L. loffe, Chem. Rev. 2003, 103, 733-772.

[13] $\beta$-bromo-substituted benzyl cation: D. Stadler, A. Goeppert, G. Rasul, G. A. Olah, G. K. S. Prakash, T. Bach, J. Org. Chem. 2009, 74, 312-318.

[14] Silylium ions in catalysis, review: a) H. F. T. Klare, M. Oestreich, Dalton Trans. 2010, 39, 9176-9184; selected recent work: b) R. K. Schmidt, K. Müther, C. Mück-Lichtenfeld, S. Grimme, M. Oestreich, J. Am. Chem. Soc. 2012, 134, 4421-4428; c) P. Ducos, V. Liautard, F. Robert, Y Landais, Chem. Eur. J., 2015, 21, 11573-11578; d) A. Rosas-Sánchez, I. Alvarado-Beltran, A. Baceiredo, N. Saffon-Merceron, S. Massou, V. Branchadell, T. Kato, Angew. Chem. 2017, 129, 10685-10690; Angew. Chem. Int. Ed. 2017, 56, 10549-10554.

[15] Processes based on in situ releasing silylium ions by exposure of stable precursors to a Brønsted acid catalyst: a) M. B. Boxer, H. Yamamoto, J. Am. Chem. Soc. 2006, 128, 48-49; b) Q.-A. Chen, H. F. T. Klare, M Oestreich, J. Am. Chem. Soc. 2016, 138, 8400-8403; c) T.
Gatzenmeier, M. van Gemmeren, Y. Xie, D. Höfler, M. Leutzsch, B. List, Science, 2016, 351, 949-952; d) Z. Zhang, H. Y. Bae, J. Guin, C. Rabalakos, M. Van Gemmeren, M. Leutzsch, M. Klussmann, B. List, Nat. Commun. 2016, 7, 12478.

[16] Activation of a silicon catalyst with a Lewis acid precatalyst: a) T. Saito, Y. Nishimoto, M. Yasuda, A. Baba, J. Org. Chem. 2006, 71, 8516-8522 b) L. Shen, K. Zhao, K. Doitomi, R. Ganguly, Y.-X. Li, Z.-L. Shen, H. Hirao, T.-P. Loh, J. Am. Chem. Soc. 2017, 139, 13570-13578.

[17] Silylium ions by gold(I) activation of silylalkynes: a) Y. Kuninobu, E. Ishii, K. Takai, Angew. Chem. 2007, 119, 3360-3363; Angew. Chem. Int. Ed. 2007, 46, 3296-3299; b) B. Rubial, A. Ballesteros, J. M. González, Adv. Synth. Catal. 2013, 355, 3337-3343; c) M. Michalska, O. Songis, C Taillier, S. P. Bew, V. Dalla, Adv. Synth. Catal. 2014, 356, 2040-2050; d) J. González, J. Santamaría, A. Ballesteros, Angew, Chem. 2015 127, 13882-13885; Angew, Chem. Int. Ed. 2015, 54, 13678-13681; e) M. Berthet, O. Songis, C. Taillier, V. Dalla, J. Org. Chem. 2017, 82, 9916-9922

[18] Catalysis from $\mathrm{SiCl}_{4}$ and a Lewis base: a) S. E. Denmark, T. Wynn, G Beutner, J. Am. Chem. Soc. 2004, 124, 13405-13407; silicon(thio)urea: b) R. Hrdina, C. E. Müller, R. C. Wende, K. M. Lippert, M. Benassi, B. Spengler, P. R. Schreiner, J. Am. Chem. Soc. 2011, 133, 7624-7627. Si-X activation by halogen bonding: c) Saito, N. Tsuji, Y. Kobayashi, Y. Takemoto, Org. Lett. 2015, 17, 3000-3003.

[19] a) A. Oku, Y. Homoto, T. Harada, Chem. Lett. 1986, 15, 1495-1498; b) M. Yasuda, T. Saito, M. Ueba, A. Baba, Angew. Chem. 2004, 116 1438-1440; Angew. Chem. Int. Ed. 2004, 43, 1414-1416; c) S. K. De, R. A. Gibbs, Tetrahedron Lett. 2005, 46, 8345-8350; d) J Y. Sawama, R. Goto, S. Nagata, Y. Shishido, Y. Monguchi, H. Sajiki, Chem. Eur. J. 2014, 20, 2631-2636.

[20] B. Mathieu, L. Ghosez, Tetrahedron 2002, 58, 8219-8226.

[21] For optimization details, stereochemical studies, characterization of products $\mathbf{3}$ and synthesis of $(S)-\mathbf{1 a}$, see the supporting information.

[22] a) C. Nieto-Oberhuber, S. López, A. M. Echavarren, J. Am. Chem. Soc 2005, 127, 6178-6179; b) N. Mézailles, L. Ricard, F. Gagosz, Org. Lett 2005, 7, 4133-4136; c) P. Pérez-Galán, N. Delpont, E. Herrero Gómez, F. Maseras, A. M. Echavarren, Chem. Eur. J. 2010, 16, 5324-5332.

[23] For gold(I) precatalysts: a) B. Ranieri, I. Escofet, A. M. Echavarren, Org. Biomol. Chem. 2015, 13, 7103-7118; for unproductive $\sigma, \pi-$ (alkyne)digold(I): b) A. Homs, C. Obradors, D. Leboeuf, A. M Echavarren, Adv. Synth. Catal. 2014, 356, 221-228; c) G. Mazzone, N. Russo, E. Sicilia, J. Chem. Theory Comput. 2015, 11, 581-590.

[24] Non-benzylic secondary electrophiles are inefficient under the two experimental conditions herein reported.

[25] Selected reviews: a) A. S. K. Hashmi, G. J. Hutchings, Angew. Chem 2006, 118, 8064-8105; Angew. Chem. Int. Ed. 2006, 45, 7896-7936; b) A. Fürstner, P. W. Davies, Angew. Chem. 2007, 119, 3478-3519 Angew. Chem. Int. Ed. 2007, 46, 3410-3449; c) Y.-M. Wang, A. D. Lackner, F. D. Toste, Acc. Chem. Res. 2014, 47, 889; d) R. Dorel, A. M. Echavarren, Chem. Rev. 2015, 115, 9028-9072.

[26] a) M. I. Bruce, N. N. Zaitseva, P. J. Low, B. W. Skelton, A. H. White, J. Organomet. Chem. 2006, 691, 4273-4280; b) E. W. Colvin, in Silicon in Organic Synthesis, Academic Press, London, 1988.

[27] GC analysis of the crude reaction mixture shows a ratio of 1,3 diphenylbut-1-yne 9 a to 3 a c.a. 5 to 1 . 


\section{Entry for the Table of Contents}

\section{COMMUNICATION}

The catalytic coupling of the title compounds affords $\beta$-halo-substituted alkynes. The cationic nature of the $\mathrm{C}$ $C$ bond-forming event is established and the actual competence of silylium species to catalyse this transformation is proved.

\section{Key Topic*}

Belén Rubial, Alfredo Ballesteros*, José M. González*

Page No. - Page No.

Silylium-Catalyzed Carbon-Carbon Coupling of Alkynylsilanes with (2Bromo-1-methoxyethyl)arenes: Alternative Approaches 